\title{
P-III: A Player-Centered, Iterative, Interdisciplinary and Integrated Framework for Serious Game Design and Development
}

\author{
Vero Vanden Abeele ${ }^{1,2}$, Bob De Schutter ${ }^{1}$, Luc Geurts ${ }^{1}$, Stef Desmet ${ }^{1}$, \\ Jeroen Wauters ${ }^{1}$, Jelle Husson ${ }^{1}$, Lieven Van den Audenaeren ${ }^{1}$, \\ Frederik Van Broeckhoven ${ }^{1}$, Jan-Henk Annema ${ }^{2}$, and David Geerts ${ }^{2}$ \\ ${ }^{1}$ e-Media Lab., Group T - International University College Leuven (Association K.U. Leuven) \\ Andreas Vesaliusstraat 13, 3000 Leuven, Belgium \\ \{vero.vanden.abeele, bob.de.schutter, luc.geurts, stef.desmet, \\ jeroen.wauters, jelle.husson, lieven.vda, \\ frederik. van.broeckh\} @groept. be \\ ${ }^{2}$ Centre for User Experience Research, K.U. Leuven / IBBT Future Health Department, \\ Parkstraat 45 Bus 3605, 3000 Leuven, Belgium \\ \{JanHenk. Annema, David. Geerts\} @soc. kuleuven. be
}

While reconciling a creative game design process with a complex software engineering process is already a daunting task, serious games add another ingredient to an already volatile mixture: the challenge of crafting an effective learning experience. In order to achieve this strenuous objective, Group T's e-Media Lab and the Centre for User Experience Research, K.U.Leuven, have developed a player-centered, iterative, interdisciplinary and integrated (P-III) framework. This framework has been developed over the course of five years of research on the design and development of serious games. Hence, P-III is built bottom-up, molded and shaped, tested and refined through several research projects $[1,9,17,18,19,20,21,22,23]$. While P-III also prescribes a specific process, in this paper we limit ourselves to highlighting the four pillars of the PIII framework, and their theoretical underpinnings.

\section{The Four Pillars of the P-III Framework}

The P-III framework offers a method for the design and development of serious games (see Figure 1). It is characterized by four conceptual pillars that are ubiquitous within the framework below:

1) Player-Centered Design: In the field of digital game development, user involvement is usually restricted to user testing in order to resolve usability issues, or to ensure that the game has a fair difficulty level $[8,10]$. Although such tests do involve the eventual player in the later stages of the process, it rarely offers players the opportunity to already participate in the creative part of the game development process. In denying the eventual player of a game from any creative input upfront, designers risk ending up with a selfreferential design. Such an 'I'-methodology is a dangerous proposition, especially when the target audience of the game differs from the game's designers $[6,15]$. Considering 
serious games, the gulf between the game developers and the target group is usually more articulated than with commercial-of-the-shelf games. Whereas game developers are still mainly male, technology savvy, and higher educated [10,16], targeted serious game players are often children, seniors, people with disabilities or of a different social economical status. For game design to lead to a worthwhile game experience, tapping into the wishes and expectations of the players is a necessity $[12,13]$. Therefore, the P-III process incorporates specific methods to involve the player throughout the design process: from ethnographically inspired inquiries at the start of the project, participatory design sessions during the design phase to user test during the development. In this sense the P-III framework adheres to a human-centered design process according to the ISO 13407 [14] standard.

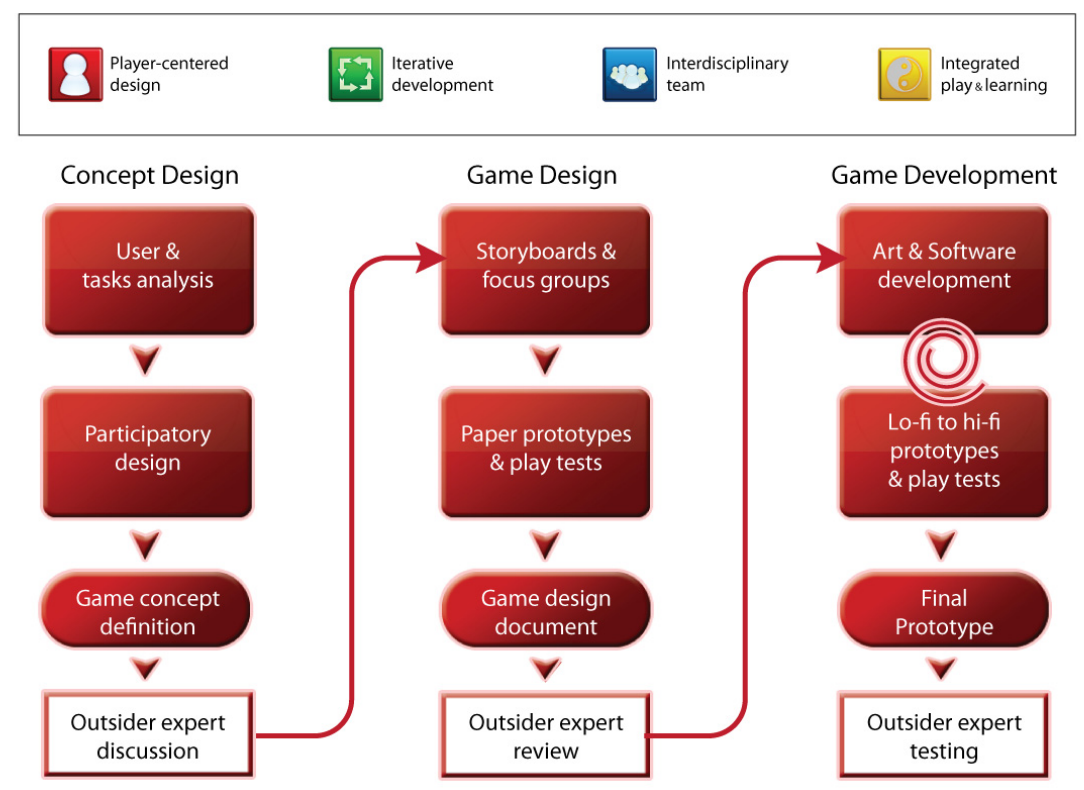

Fig. 1. An illustration of the P-III framework

2) Iterative Development: The P-III framework proposes an iterative and incremental approach to game design and development. The process evolves over several predefined phases that interact with each other (see Figure 1). The three main phases are Concept Design, Game Design and Game Development. The main focus of the Concept Design phase is to use the acquired understanding of the player group and the problem domain to come up with a first concept of what the serious game should be. After the concept design has been verified and approved, we move on to the Game Design phase. In this phase the game transforms from a concept into a detailed game that can serve as input for the game developers and digital artists. Finally, the actual Game Development process starts. The team will define different milestones and user tests throughout this phase of the process, leading up to a final prototype that can be assessed. To do so, the team will define the biggest risks the project faces (with 
regards to its learning goals, "fun" or technological challenges) and make sure that these are mitigated as soon as possible. While the exact duration of each phase depend on the specific nature of the serious game, we found that Concept Designs and Game Development typically last between three and six months, and Game Development lasts between six months and twelve months. From these numbers, one can easily understand that the sum of the analysis and design of a serious game takes as long as the actual development.

3) Interdisciplinary Teamwork: Ever since the era of the bed-room coder has ended, the game industry has been home to a heterogeneous crowd. From software engineers to visual artists, project managers and game designers, the game industry consists of many contrasting profiles. Serious game development, however, requires an even broader range of expertise. Its serious goals necessitate the involvement of social scientists, as well as experts from the serious domain of the game. In order to develop a game that is both fun to play and effective in reaching its serious goals, instructional and game designers need to collaborate [2]. P-III takes this philosophy a step further and preaches a genuinely interdisciplinary approach in which all team members, not just the designers, participate in every aspect of the development process and learn from each other's field of expertise.

4) Integration of Play and Learning: Aside from the educational potential that digital games share with simulations - such as a safe environment for experimentation alongside easy replayability - or the social context surrounding gaming, the most intriguing promise of serious games is their motivational quality [3]. To retain the motivational aspects and the flow experience [4] of digital games, academic literature has indicated that play and learning needs to be integrated as close as possible [5,6,8]. According to P-III, a successful serious game provides a seamless blend between the game fantasy and core mechanics on the one hand, and learning principles on the other. (For an overview of established learning principles that are suitable for use in digital game design, we refer to [7,11].) P-III suggests that game designers and domain experts exchange knowledge in order to choose those game mechanics that not only provoke the desired emotional responses from players, but also align with the serious objectives.

While we have presented the four characteristics as four separate pillars it is obvious that these are intertwined and reciprocal. Integration of play and learning is only possible through the interdisciplinary and intense collaboration between domain experts, user researchers, game designers and developers. Moreover, iterative and incremental development with small cycles of development alternated with user testing is innate to a player-centered design and development process. Yet, in this paper, we deemed it beneficial to unravel these for our reader in order to provide sufficient attention to each of these four characteristics. Finally, we emphasize that in this paper we have limited ourselves to describing the four pillars leaving out the specific process that the P-III framework additionally prescribes.

Acknowledgements. The work described here was conducted as part of the IWT funded e-Treasure project (TETRA-IWT nr.:60135) and the IWT-funded Theraplay project (TETRA-IWT nr.:80135). Additionally, we like to thank all participating therapists and institutions for their enthusiastic cooperation in conducting this study. 


\section{References}

1. Annema, J.-H., Verstraete, M., Vanden Abeele, V., Desmet, S., Geerts, D.: Video games in therapy: a therapist's perspective. In: Proceedings of the 3rd International Conference on Fun and Games. ACM Press (2010)

2. Egenfeldt-Nielsen, S.: Beyond Edutainment: Exploring the Educational Potential of Computer Games (2005)

3. Ermi, L., Mäyrä, F.: Player-Centred Game Design: Experiences in Using Scenario Study to Inform Mobile Game Design. Game Studies: The International Journal of Computer Game Research 5(1) (2005)

4. Federoff, M.: Heuristics and Usability Guidelines for the Creation and Evaluation of FUN in Video Games (2002), http: / / portal. acm. org/citation. cfm?id=986102

5. Flynn, S., Palma, P., Bender, A.: Feasibility of using the Sony PlayStation 2 gaming platform for an individual poststroke: a case report. Journal of Neurologic Physical Therapy 31(4), 180 (2007)

6. Gansmo, H.J., Nordli, H., Sorensen, K.H.: The Gender Game: A study of Norwegian computer game designers. In: SIGIS (2003),

http://www.rcss.ed.ac.uk/sigis/public/displaydoc/full/ D04_2.03_NTNU3

7. Garris, R., Ahlers, R., Driskell, J.E.: Games, Motivation, and Learning: A Research and Practice Model. Simulation Gaming 33(4), 441-467 (2002)

8. Gee, J.P.: What Video Games Have to Teach Us About Learning and Literacy. Palgrave Macmillan (2003)

9. Geurts, L., Vanden Abeele, V., Husson, J., et al.: Digital Games for Physical Therapy: Fulfilling the Need for Calibration and Adaptation. In: Proceedings of the Fifth International Conference on Tangible, Embedded, and Embodied Interaction. ACM (2011)

10. Gourdin, A.: Game Developer Demographics: An Exploration of Workforce Diversity. IGDA (2005)

11. Gunter, G., Kenny, R., Vick, E.: Taking educational games seriously: using the RETAIN model to design endogenous fantasy into standalone educational games. Educational Technology Research and Development 56(5), 511-537 (2008)

12. Gunter, G.A., Robert, K.F., Vick, E.H.: A Case for a Formal Design Paradigm for Serious Games (2006)

13. Hunicke, R., LeBlanc, M., Zubek, R.: MDA: A Formal Approach to Game Design and Game Research (2001)

14. International Organization for Standardization. ISO 13407:1999 - Human-centred design processes for interactive systems,

http: / / www.iso.org/iso/catalogue_detail.htm?csnumber $=21197$

15. Oudshoorn, N., Rommes, E., Stienstra, M.: Configuring the user as everybody: Gender and design cultures in information and communication technologies. Science, Technology \& Human Values 29(1), 30 (2004)

16. Saulter, J.: Diversity, the Invisible Hurdle. IGDA

17. Vanden Abeele, V., Van Rompaey, V.: Introducing human-centered research to game design: designing game concepts for and with senior citizens. In: CHI 2006 Extended Abstracts on Human Factors in Computing Systems, pp. 1469-1474. ACM (2006)

18. Vanden Abeele, V., De Schutter, B.: Designing intergenerational play via enactive interaction, competition and acceleration. Personal and Ubiquitous Computing (2010) 
19. Vanden Abeele, V., Geurts, L., Husson, J., et al.: Designing Slow Fun! Physical Therapy Games to Remedy the Negative Consequences of Spasticity. In: Proceedings of the 3rd International Conference on Fun and Games. ACM Press (2010)

20. Vanden Abeele, V., De Schutter, B., Husson, J., Vos, G., Annema, J.-H.: e-Treasure: Fostering intergenerational play by means of a digital game. In: Proceedings of Meaningful Play 2008 (2008)

21. e-Treasure (IWT-TETRA 060135) - Gebruikergestuurd ontwikkeling van een digitaal spel voor kennisuitwisseling tussen senioren en jongeren (2008), http://wiki.groept.be/confluence/display/ET/Home

22. Van Co-Design tot Playtest: een leidraad voor een Player-Centered Design process van games

23. Theraplay (IWT-TETRA 80135) - Gebruikersgestuurd ontwerp en ontwikkeling van een (ergo)therapeutische speltoepassing met sensorgestuurde bediening, http://wiki.groept.be/confluence/display/TP/Home 